\title{
Desempenho das exportações brasileiras de frutas in natura (1996-2007): uma análise sob a ótica do modelo gravitacional
}

\author{
Vinicius Vizzotto Zanchi* \\ Écio de Farias Costa** \\ Fernanda Schwantes ${ }^{* * * *}$ \\ Leonardo Ferraz Xavier ${ }^{* * * * *}$
}

\section{Resumo}

"Este trabalho estima os efeitos da distância entre o Brasil e os países para os quais exporta frutas frescas e da renda dos países envolvidos nesse comércio sobre as exportações brasileiras de frutas in natura. A análise é conduzida à luz do modelo gravitacional, ferramental teórico-analítico adotado neste estudo. O modelo considera que o comércio bilateral entre países depende do produto interno bruto, contemplando fatores indicativos de oferta e demanda potencial total dos países, e da distância entre eles, que representa fator de resistência ao comércio. Os resultados encontrados são condizentes com a teoria econômica, ratificando o efeito negativo da distância entre os países sobre o comércio de frutas frescas e o efeito positivo do produto interno bruto dos países envolvidos no comércio".

Palavras-chave: Frutas frescas. Comércio internacional. Modelo gravitacional.

* Mestre em Economia pela Universidade Federal de Pernambuco. Assistente de Unidade de Apoio do Banco do Brasil. E-mail: viniciuszanchi@gmail.com.

** PhD em Economia Agrícola pela University of Georgia. Professor adjunto IV do Departamento de Ciências Econômicas da Universidade Federal de Pernambuco. E-mail: ecio@yahoo.com.br.

*** Doutoranda em Economia Aplicada pela Universidade de São Paulo. E-mail: fe.schwantes@gmail.com.

**** Doutorando em Economia pela Universidade Federal de Pernambuco. E-mail: leonardoferraz@gmail.com.

http://dx.doi.org/10.5335/rtee.v0i41.3731

Submissão: 12/02/2013. Aceite: 26/08/2013 


\section{Introdução}

As condições edafoclimáticas e as grandes dimensões geográficas do Brasil favorecem o país na exploração da atividade agropecuária. A produção de frutas, nesse contexto, tornou-se uma alternativa viável ao baixo dinamismo de determinadas regiões brasileiras, na medida em que é responsável pela geração de 5 milhões de empregos ${ }^{1}$ e auxilia na inserção do país no comércio internacional. A fruticultura desempenha, ainda, papel de destaque na pauta do desenvolvimento endógeno agrícola brasileiro, com programas direcionados às médias e pequenas empresas (SANTOS, 2006).

O mercado internacional de frutas frescas tem se tornado cada vez mais atraente, e os produtores brasileiros buscam fazer parte desse mercado, procurando inserir seus produtos na fase "naturalista" que se vive no mundo. Faveret Filho, Ormond e Paula (1999) destacam que o aumento na expectativa de vida mundial e a busca por alimentos naturais favorecem o maior consumo de produtos in natura, permitindo a colocação adicional de frutas frescas no mercado, sejam estas tradicionais ou exóticas, as quais se constituem no grande potencial brasileiro de produção.

O Brasil possui polos produtores, como Petrolina-PE e Juazeiro-BA, que, beneficiados pelo clima tropical e por investimentos intensos em tecnologia de produção, como a irrigação, produzem frutas o ano inteiro. Assim, o Brasil destaca-se no comércio internacional de frutas frescas como o terceiro maior produtor (atrás de China e Índia), mas participando, em 2004, com apenas $2 \%$ do volume mundial exportado (SANTOS, 2006).

A União Europeia figura como o maior mercado consumidor do setor de frutas brasileiras, importando, principalmente, manga, mamão e melão. Entretanto, a Europa já tem demonstrado sinais de saturação na demanda, pois possui o mais elevado consumo per capita mundial, com destaque para a Espanha, cujo consumo per capita foi de $120 \mathrm{~kg}$, em 2005 (OLIVEIRA FILHO; COSTA; XAVIER, 2008). Além disso, o mercado europeu impõe barreiras tarifárias em período de safra, visando a proteger os produtores nacionais, e, dessa forma, o Brasil acaba suprindo esse mercado apenas em períodos de entressafra.

Ademais, outras frutas ainda não encontraram mercado e sofrem grande concorrência de outros países, como é o caso da uva brasileira, que disputa o mercado europeu com a uva sul-africana. O país sofre, também, com as barreiras fitossanitárias impostas às exportações brasileiras de frutas frescas. Os Estados Unidos, por exemplo, impõem medidas que impedem a importação de diversas frutas do Brasil, como a laranja, e, de tal modo, protegem os produtores norte-americanos, garantindo sua competitividade. 
Por outro lado, os países em desenvolvimento constituem-se em consumidores potenciais das exportações agroindustriais brasileiras, devido a fatores como urbanização, aumento da renda per capita, crescimento populacional e mudança no padrão de consumo. No entanto, a importância desses países permanece muito pequena como destino das exportações de frutas, tendo a Argentina sido o único país não desenvolvido, em 2008, a aparecer como um dos principais destinos para as frutas brasileiras.

A logística é considerada um entrave à competitividade, modernização e ao avanço da fruticultura brasileira. A precariedade de condições de produção e comercialização desestimula muitos produtores e, assim, o comércio existente de frutas in natura não atinge escala suficiente que justifique o funcionamento de estruturas de armazenamento apropriadas. Por ser um produto com alto grau de perecibilidade, a fruta fresca necessita chegar ao consumidor em curto espaço de tempo, de forma a conservar suas melhores características, ou ser armazenada em condições climáticas adequadas.

Diante dos aspectos abordados acima, este artigo procura examinar os efeitos da distância entre o Brasil e os países importadores de frutas frescas, e da renda dos países envolvidos nesse comércio sobre as exportações brasileiras de frutas in natura, à luz do modelo gravitacional. Essa análise torna-se relevante na medida em que a distância física entre o Brasil e cada um dos principais importadores mundiais de frutas frescas brasileiras representa o efeito das barreiras geográficas ao comércio internacional do produto, constituindo-se em variável proxy dos custos de transporte envolvidos no comércio e das condições de infraestrutura. A questão da logística e infraestrutura é fundamental para a fruticultura e pode definir o acesso ou não a um mercado consumidor. Essa questão depende, fundamentalmente, de interesses convergentes entre os setores público e privado.

Procura-se avaliar, ainda, a influência da renda interna e do poder de compra dos países importadores, dado pelo seu produto interno bruto (PIB). Os níveis de renda dos países importadores permitem caracterizar os seus perfis e, por conseguinte, o rumo que o governo deve tomar frente a acordos bilaterais e multilaterais de comércio. A participação ínfima do Brasil no comércio mundial de frutas frescas contrasta com a capacidade e potencialidade produtiva brasileira. Mais do que diversificar e aumentar as cifras das exportações brasileiras, esse setor atua com papel fundamental na geração de empregos e renda para regiões carentes do Brasil. A análise compreende o período de 1996 a 2007.

Este artigo está organizado em seis seções, sendo a primeira constituída por esta introdução. Na seção 2, faz-se uma caracterização do desempenho do Brasil no mercado internacional de frutas frescas. A seção 3 apresenta o referencial teórico, 
destacando os fundamentos do modelo gravitacional. Na seção 4, encontra-se o referencial analítico, a definição das variáveis e a fonte de dados. A seção 5 reúne os resultados da pesquisa, e, finalmente, a seção 6 apresenta as principais conclusões do estudo.

\section{Desempenho brasileiro no comércio internacional de frutas frescas}

O comércio internacional de frutas ganhou importância a partir da década de 1990. Faveret Filho, Ormond e Paula (1999), baseados em relatório da Organisation for Economic Co-operation and Development (OECD, 1996), apontam quatro fatores que possibilitaram a enorme expansão da fruticultura no mundo. O primeiro refere-se ao empenho dos países em desenvolvimento em aumentar o valor exportado e diversificar as suas pautas de exportação. Essa atitude foi tomada devido à crise na década de 1980, que afetou os preços das commodities tropicais. $\mathrm{O}$ segundo fator corresponde à liberalização do comércio proporcionada pela conclusão da Rodada do Uruguai, em 1994, e uma série de acordos bilaterais e regionais que permitiram a diminuição das barreiras comerciais. $O$ terceiro fator consiste na diversificação produtiva, estratégia de proteção dos países frente à diminuição das garantias do governo e reforma da política agrícola. $\mathrm{O}$ último fator constitui-se no avanço da capacidade de transporte e armazenagem das frutas. O melhoramento nessas técnicas possibilitou um tratamento pós-colheita reduzido e o colhimento de frutas mais maduras.

O mercado mundial de frutas é dominado por produtos de clima temperado e que possuem seus maiores mercados consumidores na Europa e nos Estados Unidos. Faveret Filho, Ormond e Paula (1999) avaliam que é necessário ter cautela quando se analisa dados de produção e comercialização de frutas, pois algumas são predominantemente consumidas e comercializadas in natura, e outras, com algum processo industrial. As frutas predominantes no cenário mundial são a laranja, a maçã, a uva, a banana, o pêssego, a pera e o abacaxi. As que possuem maior consumo in natura são a banana, a pera e o abacaxi, enquanto a laranja e a maçã são consumidas, predominantemente, em forma de suco; a uva, em vinhos ou suco; e o pêssego, em compota. Embora não tenham grande participação no comércio internacional, as frutas exóticas de clima tropical encontram consumidores potenciais nos países desenvolvidos (principalmente nos Estados Unidos), como é o caso da goiaba, da manga, do mamão e do kiwi. 
A potencialidade produtiva da fruticultura brasileira encontra-se tanto em frutas tropicais como nas de clima temperado. Na região Nordeste, por exemplo, diversos aspectos estimulam a produção de frutas das duas categorias. Em primeiro lugar, evidencia-se a disponibilidade de solo e recursos hídricos de boa qualidade. Em segundo lugar, aponta-se a abundância de mão de obra. A terceira vantagem diz respeito às condições climáticas, pois a alta insolação e a baixa umidade do ar reduzem as chances de doenças e pragas. Como quarto fator, pode-se apontar a ocorrência de um ciclo produtivo reduzido, permitindo mais de uma safra por ano (GONÇALVES; SOUZA, 1998).

Ademais, a abertura comercial ocorrida na década de 1990 foi crucial para o aprimoramento da fruticultura brasileira. Goebel (2002) explica que esse processo permitiu o acesso a novas técnicas e tecnologias, assim como a insumos mais eficientes e de melhor qualidade. Do mesmo modo, o autor identifica que, para atingir padrões internacionais, os produtores perceberam a necessidade de investimentos em produtividade, qualidade, conhecimento e inovação.

Santos (2006) aponta que o comércio mundial de frutas é altamente competitivo. Como exemplo disso, tem-se a situação do Brasil, cujo market share em 2004 era o mesmo de 1970. Por outro lado, com um volume exportado três vezes maior. Oliveira Filho, Costa e Xavier (2008) alertam para a importância da análise da sazonalidade, uma vez que a maior parte do comércio internacional de frutas restringe-se ao hemisfério norte. Os produtores brasileiros podem se aproveitar dessa característica e identificar os melhores períodos para exportar, quando as janelas de mercado estão abertas e ocorre a redução das barreiras tarifárias.

Gayet (1999) caracteriza o comércio internacional de frutas frescas como "mercados de proximidades", onde a região produtora e consumidora são relativamente próximas, com menores custos de transportes. Esse é um fator que pode justificar a reduzida participação brasileira nas exportações mundiais de frutas. Porém, de acordo com o autor, a principal razão do módico desempenho brasileiro é o grande mercado interno existente, que é muito menos exigente e bastante lucrativo.

Um dos poucos exemplos de polos brasileiros de frutas voltados para a exportação é o de Petrolina-PE e Juazeiro-BA, no Vale do São Francisco. Oliveira Filho, Costa e Xavier (2008), com base nos dados do Rabobank, expõem a importância e o potencial desse polo. Em 2004, 86\% da manga brasileira exportada foi proveniente desse polo, índice muito superior aos $32 \%$ observados em 2003 . No caso da uva, a importância é ainda maior, tendo 99\% da uva exportada em 2004 sido produzida no Vale do São Francisco. Em 2003, a relação alcançava apenas 17\%. 
Ainda no contexto do comércio internacional de frutas, um dos fatores de maior relevância são as barreiras fitossanitárias, conforme destacam Faveret Filho, Ormond e Paula (1999). Quase todos os países colocam restrições ao comércio de alimentos, principalmente os frescos. No caso de frutas, em especial, os cuidados precisam ser redobrados, pois um lote infectado pode custar os esforços de anos de combate a pragas e doenças.

Visando a identificar os principais fatores que dificultam as exportações frutícolas brasileiras, Oliveira Filho, Costa e Xavier (2008) apontam o transporte inadequado, embalagens e produtos com especificações em desacordo com o mercado e a não utilização de câmaras frias. Gonçalves e Souza (1998), ao comparar as razões para o forte desempenho do Chile, que se apresenta no cenário internacional como um dos maiores exportadores de frutas, contrastando com a acanhada participação brasileira, identificaram algumas desvantagens que o Brasil apresenta frente ao Chile.

Como primeiro fator, os autores supracitados apontam que o comércio mundial de frutas está dominado por grandes empresas, as trading companies, que possuem excelentes estruturas pós-colheita, armazenagem e distribuição, preenchendo os requisitos dos consumidores dos países importadores. A cadeia fruticultora chilena é caracterizada pela forte presença dessas empresas que controlam a produção e o sistema logístico e abrem janelas para os produtos chilenos em mercados que dominam. No Brasil, as estruturas logísticas ainda são muito ineficientes, muitas vezes, sem equipamentos adequados, o que eleva custos e diminui a competitividade do produto. O Brasil possui um sistema ineficaz de controle, regulação e fiscalização do mercado de frutas. Esse fato impossibilita a preparação e adequação com vistas a atender mercados exigentes, que requerem produtos com embalagens bem detalhadas, e abre concorrência no mercado interno para frutas importadas de melhor qualidade.

Como segundo fator, os autores supramencionados afirmam que os grandes importadores impõem várias barreiras tarifárias e fitossanitárias para garantir um produto importado de alta qualidade, para o controle de doenças e pragas e para a proteção dos produtores locais, os quais já recebem subsídios elevados. Entretanto, o Brasil praticamente não faz imposição alguma para o seu mercado interno, permitindo até que produtores nacionais sofram as consequências diante de ações de dumping cometidas por outros países. A importância dos controles fitossanitários é evidenciada, ainda, no trabalho de Neves et al. (2001), que, em estudo sobre a citricultura brasileira, indicavam que a laranja in natura é impossibilitada de acessar os Estados Unidos por estar fora das especificações técnicas. Já na Europa, o motivo é que o Brasil não é um país livre de doenças como pinta-preta e cancrocítrico. Dessa forma, o Brasil somente consegue acessar o mercado de alimentos desses países por meio de laranjas processadas em forma de suco. 
Como terceiro ponto destacado está o pesado sistema tributário brasileiro, aliado à política de juros altos, os quais aumentam os custos dos empréstimos e inviabilizam o investimento na produção e modernização da fruticultura nacional. Ademais, existe a carência de uma política nacional que estimule a complementaridade de frutas regionais na cesta da população. Isso estimularia 0 consumo interno e levaria a uma alimentação mais nutritiva com frutas de vários tipos, cores e tonalidades.

Ainda, estudos como os de Passoni et al. (2006) e Nachreiner, Santos e Boteon (2003) apontam os principais motivos para a fraca atuação brasileira nas exportações de frutas frescas. Esses trabalhos mostram que, apesar de uma sucessiva melhora na sua qualidade, as frutas continuam sendo alvo de constantes reclamações por parte dos europeus, cabendo destacar que a União Europeia constitui-se no principal destino das exportações brasileiras de frutas frescas. Em 2005, 85\% das exportações brasileiras de frutas in natura foram para a União Europeia e $10 \%$ para os países do NAFTA. Isso pode gerar um efeito de saturação no futuro e prejudicar fortemente o setor. Uma importante atenuação desse cenário seria $o$ acesso ao mercado da China. Entretanto, problemas burocráticos, altos custos de transporte e falta de acordos entre os governos brasileiro e chinês levam a que os exportadores insistam em concentrar suas exportações em mercados tradicionais.

A infraestrutura das estradas do Nordeste e dos portos também é apontada como desestímulo à exportação. $\mathrm{O}$ principal porto brasileiro utilizado para a exportação de frutas é o de Salvador. Porém, em certos períodos, as cargas sobrecarregam a capacidade do porto e ocorrem diversos atrasos, gerando custos extras de armazenagem e possível perda de qualidade das frutas. Num setor em que $35 \%$ do preço final do produto é devido a gastos com transporte, o sistema logístico torna-se um ponto crucial para as exportações brasileiras de frutas.

Os padrões exigidos de qualidade, as embalagens, as pragas, as doenças e os problemas diplomáticos são exemplos de barreiras não tarifárias que barram o acesso de muitos produtores ao cenário internacional. Acordos bilaterais podem levar décadas até que um país permita a entrada de determinadas frutas em seu território, a exemplo da manga brasileira no mercado japonês. Já as barreiras tarifárias representam um claro aumento no preço final do produto e perda de competitividade dos produtores e exportadores.

Muitas vezes, o simples desconhecimento de frutas tropicais retrai a demanda de grandes mercados consumidores. Em um mercado dominado por frutas de clima temperado, a divulgação de frutas tropicais e o conhecimento do tipo de fruta que é mais bem recebido em determinada região podem contribuir fortemente com 0 
crescimento das exportações. Foi nesse sentido que, em 2006, o Brasil iniciou campanhas a fim de divulgar as frutas brasileiras em supermercados de vários países do mundo.

Finalmente, ressaltam-se a reduzida utilização de contratos pré-estabelecidos entre importador e exportador - criando uma enorme instabilidade ao gerar divergências dos produtos entregues com os acordados e prejudicando o aumento da confiança no mercado - e a valorização do Real a partir de 2003, que se mostrou como o principal empecilho para as exportações de todos os setores. Essa perda de competitividade pode desestimular novos investimentos no setor exportador, prejudicando o crescimento da fruticultura.

\section{Referencial teórico}

O referencial teórico que sustenta o problema de pesquisa em estudo relaciona-se com as teorias de comércio internacional, especialmente as teorias que embasam os desenvolvimentos da especificação do modelo gravitacional.

\subsection{Desenvolvimentos da especificação do modelo gravitacional}

Os benefícios do livre comércio internacional remontam aos autores clássicos Adam Smith e David Ricardo, que se opunham às concepções mercantilistas (séculos XVI, XVII e XVIII), baseadas no protecionismo, no favorecimento da regulamentação comercial e nos subsídios às exportações como forma de acúmulo de metais preciosos. A teoria clássica emerge sustentando a livre escolha dos agentes e o liberalismo econômico e procura evidenciar que a especialização produtiva assegura aos países ganhos de bem-estar caso comercializem entre si o aumento da riqueza global.

Inicialmente, Adam Smith (1776) propôs a teoria das vantagens absolutas, segundo a qual cada país deve concentrar seus esforços de produção nos produtos que consegue produzir a custos absolutos mais baixos e trocar os excedentes de produção por produtos que custem menos em outros países. A especialização da produção contribui, portanto, para o aumento de bem-estar, na visão de Smith, na medida em que eleva a produtividade dos insumos de produção e a eficiência técnica dos países, fatores determinantes dos custos e da competitividade internacional.

David Ricardo (1817), que discutiu e aprimorou a teoria das vantagens absolutas de Smith, advertiu que, de acordo com essa teoria, o país que possuísse produtividade menor em todos os produtos não poderia participar do comércio internacional. 
Ricardo desenvolveu a teoria das vantagens comparativas ou relativas, afirmando que o comércio bilateral pode ocorrer mesmo que um país seja absolutamente menos eficiente na produção de todos os bens. Conforme o autor, são as diferenças de custos de oportunidade na produção entre os países que definem em quais produtos as nações são relativamente mais eficientes (possuem vantagens comparativas) e, portanto, devem se especializar.

A especialização produtiva de cada nação no bem sobre o qual possua vantagem comparativa e a realização de trocas comerciais possibilitam a diversificação de produtos e a elevação dos volumes produzidos mundialmente, e, por conseguinte, da quantidade consumida, de modo que nenhuma nação desejará produzir de forma autárquica, como fazia antes da abertura dos mercados. Além disso, o aumento na produção individual de cada país, por meio da especialização, acarreta na expansão da curva de possibilidades de produção dos países envolvidos, e, consequentemente, num nível maior de qualidade do produto após o comércio. Assim, Ricardo afirma que o comércio será benéfico para ambas as nações, levando ao crescimento econômico mundial e à elevação do bem-estar de todos os países envolvidos nos fluxos comerciais.-

De acordo com Jayme Jr. (2001), a teoria das vantagens comparativas de Ricardo, em versão atual, sugere que a alocação mais eficiente de recursos econômicos possibilita a importação de bens e serviços que só poderiam ser produzidos internamente a um custo superior. Contudo, o modelo ricardiano consiste num modelo estático, baseado em concorrência perfeita dos participantes no comércio internacional. Além disso, assume ausência de custos de transporte, desconsidera ganhos de escala e admite padrões tecnológicos fixos, o que, segundo Jordán e Parré (2006), são características dos modelos tradicionais de comércio internacional.

Ainda sob a abordagem de especialização produtiva, a teoria de Hecksher-Ohlin identifica a diferença nas dotações de fatores como determinante das vantagens comparativas de um país e como causa do comércio. O modelo Heckscher-Ohlin (H-O) postula que cada país irá produzir e exportar o bem intensivo no fator (mão de obra ou capital) que for mais barato e abundante internamente. Assim, o comércio internacional, além dos ganhos de produtividade, permite a equalização dos preços dos fatores, visto que estes tendem a migrar para os lugares nos quais são mais bem remunerados.

Entretanto, o modelo de Heckscher-Ohlin (H-O), apesar de considerar que os produtos possuem produtividades marginais positivas, mas decrescentes, e retornos constantes de escala, reconhece que não há possibilidade de reversão na intensidade de uso dos fatores e que a estrutura de demanda é idêntica nos dois países. 
Assim, o modelo H-O admite que, dado qualquer preço relativo dos insumos e dos produtos, a proporção segundo a qual os dois bens são produzidos e consumidos independe do nível de renda (JAYME JR., 2001).

Porter (1993), contudo, entende que os pressupostos baseados em vantagens comparativas em que se constituem as teorias do comércio internacional, não são condizentes com a realidade. Sob o aspecto competitivo, o comércio internacional passa a ser influenciado por outras variáveis, além da dotação de fatores como progresso e difusão tecnológica, especialização das firmas, ampliação dos canais de comunicação entre países, estrutura de incentivos como tarifas de importação e subsídios à exportação, preços, custos dos fatores, taxas de câmbio, taxas de paridade entre os parceiros comerciais, custos de transporte, barreiras tarifárias e não tarifárias, etc.

Nesse contexto, surgem as novas teorias de comércio internacional (New Trade Theories) para explicar o comportamento dos fluxos comerciais cujas bases estão fundamentadas em concorrência imperfeita e comércio intraindústria ${ }^{2}$. Segundo Jórdan e Parré (2006), de acordo com essa corrente teórica, o que determina a pauta de exportação de um país são, dentre outros fatores, as dimensões do mercado interno, de tal forma que os países não exportam apenas produtos nos quais têm vantagens comparativas, mas também aqueles que o mercado doméstico permite produzir em maior quantidade pela presença de rendimentos crescentes de escala em condições de competição imperfeita.

$\mathrm{Na}$ perspectiva das novas teorias de comércio internacional, delineou-se, no início dos anos 1960, o modelo gravitacional, com os trabalhos pioneiros de Tinbergen (1962), Poyhonen (1963) e Linnemann (1966). Segundo Azevedo (2004), esses trabalhos forneceram as variáveis básicas e suas proxies para determinar o comércio bilateral entre países, fatores que indicam a oferta e demanda potencial total dos países, nos quais o produto interno bruto constitui-se em uma proxy, e a resistência ao comércio entre eles, dada pela distância. Assim, a forma mais simples da equação de gravidade aplicada ao comércio bilateral entre países é dada por:

$$
M_{i j t}=\alpha_{1} d_{i j}^{\beta 1} y_{i t}^{\beta 2} y_{j t}^{\beta 3}
$$

em que $M_{i t j}$ é o comércio bilateral, seja em importações ou exportações nominais, ou a soma de ambas, do país $i$ para o país $j$; $y_{i t}$ é a renda (PIB) do país exportador no período $t ; y_{j t}$ é a renda (PIB) do país importador no período $t ; d_{i j}$ é a distância entre o país $i$ e o país $j$ e $\beta_{1} \beta_{2}$ e $\beta_{3}$ são parâmetros que se espera que tenham sinal positivo, à exceção de $\beta_{r}$. 
A expectativa é de que os volumes comercializados aumentem com o tamanho das economias dos países, uma vez que, quanto maior a economia do país exportador, maior a variedade de produtos disponíveis para exportação, e, quanto maior a economia do país importador, maior é o gosto pela variedade no consumo. Por outro lado, a distância entre dois países serve como proxy para a resistência ao comércio, captando efeitos de variáveis como tempo, custos de transporte e custos de informação.

Embora, durante a década de 1960, o modelo gravitacional tenha sido utilizado sem fundamentação teórica, apenas porque se ajustava bem a aplicações empíricas de explicação dos fluxos bilaterais de comércio, a partir do final da década de 1970, a equação gravitacional passou a ter sustentação teórica de vários modelos de fluxos de comércio, desde a teoria $\mathrm{H}-\mathrm{O}$ até a criação e o desvio de comércio decorrentes de acordos regionais, como aponta Fratianni (2007).

Em 1980, Krugman desenvolveu o modelo de comércio entre dois países que competem monopolisticamente (cada país é especializado em bens diferenciados) e constituiu a justificativa teórica mais difundida para a utilização da equação gravitacional, segundo Flach (2008). A análise de Krugman refere-se à existência de retornos crescentes na produção e nos custos de transporte, fatores que atuam como um incentivo à concentração da produção de um produto próximo a um grande mercado, mesmo que exista demanda por esse bem em mais algum mercado.

Krugman desenvolveu esse modelo para caracterizar o que denominou de "efeito mercado doméstico", no qual se admite que dois países (um grande e outro pequeno) produzam a mesma variedade de produto, sob o mesmo preço em ambos os locais. Como o país maior terá demanda mais acentuada por produtos diferenciados, um maior número de empresas entrará no seu território para produzir. Logo, o país maior tende a tornar-se um exportador líquido dos bens para os quais dispõe de uma demanda doméstica relativamente grande, o que possibilita a geração de economias de escala. Assim, países pequenos com mercados absolutamente pequenos terão de compensar essa desvantagem de custo com salários relativamente mais baixos.

\subsection{Estudos empíricos}

Bergstrand (1989) utiliza-se do modelo gravitacional para estimar o comércio por grupos de produtos, embasado nos pressupostos da dotação de fatores do modelo H-O. O autor conclui que dois setores similares (em países distintos) podem produzir o mesmo item com diferenciação somente na presença de mercados em 
concorrência monopolística. Mata e Freitas (2008) explicam que esse argumento, numa roupagem moderna, sinaliza para a identificação de nichos de mercado sob concorrência não perfeita.

Deardoff (1998), da mesma forma, mostra que o modelo gravitacional é condizente com a teoria de $\mathrm{H}-\mathrm{O}$. O autor, ao comparar mercado de concorrência perfeita e o mercado de concorrência monopolística, concluiu que o modelo gravitacional aplica-se tanto a produtos homogêneos quanto a produtos diferenciados. Em concorrência perfeita, não há barreiras ao comércio (inclusive custos de transporte), e, assim, os fluxos de comércio são determinados apenas pelo poder de compra dos mercados consumidores. Em concorrência monopolística, a presença de barreiras ao comércio, inclusive os custos de transporte, evidencia que o comércio depende da distância entre os parceiros comerciais, além da sua renda (PIANI; KUME, 2000).

No Brasil, a aplicação do modelo de gravidade foi proposta, inicialmente, por Hidalgo e Vergolino (1998). Os autores avaliaram as características do comércio da região Nordeste com as demais regiões do país e com outros países, cuja análise desenvolveu-se em torno dos impactos das fronteiras diante dos padrões de comércio regional e internacional. Os autores afirmaram que, mais do que avaliar a influência da distância e da renda dos países, o modelo de gravidade é capaz de mensurar os efeitos de integração econômica, de desvio e de criação de comércio.

Piani e Kume (2000) analisaram a evolução dos fluxos bilaterais de comércio entre 44 países e, em especial, os efeitos de acordos preferenciais de comércio entre 33 desses países, reunidos em seis blocos econômicos, no período de 1986 a 1997. A análise dos autores confirmou a importância dos vários tipos de acordos regionais de livre comércio para a elevação dos volumes comercializados, bem como da adjacência e do idioma comum. Segundo os autores, para os países analisados, dois países adjacentes comercializam, em média, cerca de $100 \%$ a mais entre si do que outro par de países similares que não compartilham fronteira.

Castilho (2002) estimou equações gravitacionais por setores de atividade econômica, visando a mensurar a sensibilidade das importações da União Europeia provenientes dos seus 92 principais parceiros frente às barreiras comerciais impostas por aquele bloco e, mais especificamente, os benefícios para o MERCOSUL advindos da liberalização bilateral. As estimações da equação gravitacional incluíram, por exemplo, distância e língua comum como variáveis explicativas. Os coeficientes estimados para distância foram negativos e significativos. No caso da língua comum, detectou-se uma influência positiva sobre os fluxos comerciais bilaterais, o que denota, segundo a autora, a influência das ex-metrópoles nos acordos comerciais. 
Mata e Freitas (2008) estimaram o modelo gravitacional para as exportações agropecuárias brasileiras e concluíram que a distância dos mercados compradores é a variável que exibe maior impacto individual negativo sobre as vendas brasileiras de produtos agropecuários, enquanto que incrementos na renda e na população dos mercados consumidores afetam positivamente as exportações agropecuárias.

\section{Metodologia}

Nesta seção, apresenta-se a especificação do modelo estimado, bem como os procedimentos econométricos necessários para estimar a regressão. Além disso, definem-se as variáveis empregadas e a fonte de dados.

\subsection{Modelo analítico e procedimentos}

Para a estimação da equação de gravidade, a equação (1) foi tomada em sua forma logaritmizada, de modo que os coeficientes $\beta_{i}$ medem a elasticidade da variável dependente em relação a variações em cada um dos respectivos regressores, obtendo-se a seguinte forma funcional:

$$
\ln M_{i j t}=\alpha_{1}+\beta_{1} \ln d_{i j}+\beta_{2} \ln y_{i t}+\beta_{3} \ln y_{j t}+\mu_{i j t}
$$

em que $M_{i j t}$ são as exportações de frutas frescas do Brasil para os 20 principais importadores do produto (a lista completa com os países considerados na amostra encontra-se no Apêndice 1 deste trabalho); $d_{i j}$ é a distância entre o Brasil e cada um dos parceiros comerciais para o produto; $y_{i t}$ é a renda do Brasil; $y_{j t}$ é a renda de cada um dos importadores no período considerado; $\mu_{i j t}$ é o resíduo; $i$ corresponde ao Brasil, $j=1,2,3, \ldots, 20$ são os principais importadores de frutas frescas brasileiras e $t=1,2, \ldots, 12$ é o período de tempo considerado no estudo, em anos, de 1996 a 2007, totalizando 240 observações.

A equação (2) trata-se de uma regressão combinada, que empilha as informações temporalmente. Ela pode ser computada por Mínimos Quadrados Ordinários (MQO), método que desconsidera as individualidades de cada país ao empilhar todas as observações e pressupor que todos os coeficientes (intercepto e coeficientes angulares) são constantes ao longo do tempo e entre as diferentes unidades de corte transversal, neste estudo, especificamente os países importadores de frutas frescas do Brasil. 
Azevedo (2004) aponta que o modelo gravitacional tem sido frequentemente estimado, por meio de MQO. Entretanto, o autor supracitado explica que, como o modelo gravitacional envolve, na maioria dos casos, um número elevado de países e anos, é muito provável que, para algumas observações, a variável dependente (exportações, importações ou comércio total) assuma o valor zero, não permitindo a transformação logarítmica. Nesse caso, diz-se que a variável dependente é censurada em parte da amostra, ou seja, a informação está omissa para a variável dependente, mas está presente para as variáveis explanatórias (PINDYCK; RUBINFELD, 2004). Diante disso, a literatura tem adotado três procedimentos para tratar desse problema.

O primeiro tem sido eliminar as observações com valores igual a zero, considerando somente aqueles com valores positivos. Azevedo (2004) explica que essa abordagem certamente não é a mais apropriada, pois não leva em consideração as informações relevantes sobre as razões pelas quais ocorrem baixos níveis de comércio. Ainda, segundo Pindyck e Rubinfeld (2004), a estimação por MQO do modelo de regressão censurada produz estimativas de parâmetros tendenciosas e inconsistentes, pois a censura introduz uma correlação entre o termo de erro da regressão e as covariáveis $X$ (FERREIRA; BRAGA, 2007).

$\mathrm{O}$ segundo procedimento tem sido substituir os valores iguais a zero por valores muito pequenos, tais como 0,001 , antes de fazer a transformação logarítmica, ao invés de simplesmente descartar essas observações, e fazer a estimação por MQO. Entretanto, o logaritmo de um número muito pequeno é um número negativo muito grande e, como a técnica de $\mathrm{MQO}$ dá uma ponderação maior para os valores extremos, essas observações recebem um peso muito grande nas estimativas.

$\mathrm{E}$, finalmente, uma terceira abordagem trata diretamente os dados da amostra censurada para a variável endógena ao empregar o modelo tobit, um estimador de máxima verossimilhança consistente. Esse procedimento incorpora informação implicitamente nas observações iguais a zero, com as observações positivas sendo utilizadas para estimar o valor do comércio, dado que ele é positivo, enquanto que as observações iguais a zero são usadas para estimar a probabilidade de o comércio ser positivo.

De acordo com Wooldridge (2008), o modelo tobit expressa a resposta observada, $(y)$, em termos de uma variável latente subjacente, $\left(y^{*}\right)$, tomando a seguinte formulação geral: 


$$
\begin{aligned}
& y^{*}=x \beta+\mu \\
& y=\max \left(0, y^{*}\right)
\end{aligned}
$$

em que

$$
\begin{gathered}
y=y^{*} \text { se } y^{*}>0 \\
y=0 \text { em caso contrário }
\end{gathered}
$$

Na equação (3), o termo $x$ representa o vetor de variáveis explicativas e, conforme já definido na equação (2), $\beta$ é o vetor dos parâmetros estimados e $\mu$ é o termo de erro.

O método de máxima verossimilhança para a obtenção das estimativas dos coeficientes $\beta$, possibilita isolar e descrever a contribuição das variáveis censuradas, bem como das variáveis não censuradas, na formação da função de verossimilhança (FERREIRA E BRAGA, 2007). Assim, por levar em conta explicitamente as observações para as quais não se tem informação, o método de máxima verossimilhança produz estimativas confiáveis em relação às estimativas por MQO.

Segundo Greene (2008), as estimativas do modelo tobit não produzem resultados imediatos, já que os coeficientes $\hat{\beta}$ medem os efeitos parciais das variáveis $X$ sobre a variável latente, $y^{*}$, e, por isso, não podem ser interpretados diretamente. Assim, calcula-se o efeito marginal das variáveis explicativas sobre a variável dependente, que pode ser obtido por meio da seguinte fórmula, derivada em Wooldridge (2008, p. 533):

$$
\frac{\partial E(y / x)}{\partial x}=\beta_{j} \phi\left(\frac{\beta x}{\sigma}\right)
$$

em que $x$ é o vetor de variáveis explicativas do modelo, $\beta$ é o vetor de coeficientes estimados de cada uma das variáveis; e $\sigma$, o desvio padrão.

\subsection{Definição, descrição e fonte dos dados}

Os dados correspondentes às exportações brasileiras de frutas frescas para cada país importador, em dólares, foram obtidos junto à Secretaria de Comércio Exterior (SECEX), a partir do sistema ALICEWeb. As frutas para as quais se obteve dados são: uva (código NCM 08061000), melão (08071900), manga (08045020), maçã (08081000), banana (08030000), limão (08053000 e 08055000), mamão 
papaia (08072000), laranja (08051000), abacaxi (08043000) e melancia (08071100), as quais correspondem a $96 \%$ do valor total exportado de frutas pelo Brasil.

A distância considerada consiste na linha reta, em quilômetros, entre Brasília e a capital de cada país. Tal metodologia segue o trabalho de Castilho (2001) e difere de alguns trabalhos que utilizam a distância entre portos. Seria difícil estabelecer um porto brasileiro como referência frente às mudanças ocorridas na pauta de exportações brasileiras de frutas, as quais são produzidas nas mais diferentes regiões do país. Ademais, a autora aborda que as diferentes medidas usadas nos modelos gravitacionais convergem quando se analisam longas distâncias. O programa utilizado para tais informações foi o Google Earth (GOOGLE, 2009).

O PIB do Brasil e dos 20 principais importadores das frutas frescas brasileiras, em bilhões de dólares, ajustados pelo sistema de paridade do poder de compra, foram obtidos junto ao Fundo Monetário Internacional (FMI) (2009).

\section{Resultados e discussão}

Esta seção apresenta os resultados obtidos no presente estudo, em três partes. A primeira parte apresenta a análise descritiva das variáveis gravitacionais consideradas determinantes das exportações brasileiras de frutas frescas, ao longo do período de 1996 a 2007. A segunda parte ilustra o comportamento das exportações de frutas in natura para os 20 principais importadores do produto do Brasil. A terceira parte contempla o modelo econométrico estimado, que permite mensurar os efeitos das variáveis gravitacionais sobre as exportações de frutas frescas do Brasil.

\subsection{Análise descritiva das variáveis gravitacionais determinantes das exportações brasileiras de frutas frescas}

A Tabela 1 relaciona as estatísticas descritivas das variáveis quantitativas empregadas como determinantes das exportações brasileiras de frutas frescas, a citar: renda nacional, renda externa e distância entre o país de origem e o país importador. 
Tabela 1. Estatísticas descritivas das variáveis quantitativas utilizadas como determinantes das exportações brasileiras de frutas frescas no período compreendido entre 1996 e 2007

\begin{tabular}{l|r|r|r|r}
\hline \multicolumn{1}{c|}{ Variável } & \multicolumn{1}{c|}{ Média } & Desvio padrão & \multicolumn{1}{c|}{ Mínimo } & \multicolumn{1}{c}{ Máximo } \\
\hline expbr $_{i j t}$ (milhões US\$) & 13,3 & 30,80 & 0,00 & 242,00 \\
$\operatorname{dist}_{i j}(\mathrm{~km})$ & $9.138,25$ & $3.581,23$ & $2.265,00$ & $17.653,00$ \\
$y b r_{i t}$ (bilhões US\$) & $1.360,51$ & 238,29 & $1.068,27$ & $1.845,36$ \\
yext $_{j t}$ (bilhões US\$) & $1.524,09$ & $2.408,03$ & 24,56 & $13.807,55$ \\
\hline
\end{tabular}

Número de observações: 240

Fonte: Dados da pesquisa.

As estatísticas descritivas indicam que as exportações brasileiras de frutas in natura (expbr $r_{i j t}$ ) foram, em média, de 13,3 milhões de dólares ao ano, com desvio padrão em torno de 30,8 milhões de dólares. Nos períodos em que não houve comércio, ou seja, naqueles em que os mercados importadores não compraram frutas in natura do Brasil, as observações assumem valor zero (mínimo) e essas observações são censuradas na estimação pelo método tobit. O valor máximo exportado de frutas frescas pelo Brasil, no período em análise, foi de 242,26 milhões de dólares, correspondente às exportações do produto para os Países Baixos, em 2007, o qual destaca-se, desde 2003, como principal importador mundial de frutas in natura produzidas no Brasil.

As exportações para os países baixos representaram, em 2007, 39,74\% do total das vendas externas brasileiras do produto aos 20 principais parceiros comerciais. Em seguida, destaca-se o Reino Unido, cujas importações de frutas in natura oriundas do Brasil correspondem a 22\% dos 609,66 milhões de dólares exportados em frutas, em 2007. Listam, ainda, entre importantes mercados consumidores do produto brasileiro, em 2007, a Espanha, cujas importações corresponderam a 7,72\% das exportações brasileiras de frutas in natura, os Estados Unidos com 7,35\% e a Alemanha 4,8\%.

A variável distância $\left(d_{i j}\right)$ aponta que, em média, os parceiros comerciais do Brasil para as exportações brasileiras de frutas frescas, localizam-se 9.138,25 km distantes do Brasil. Os países importadores de frutas frescas que localizam-se mais próximos ao Brasil são o Uruguai $(2.265 \mathrm{~km})$, a Argentina $(2.332 \mathrm{~km})$ e os Estados Unidos (6.760 km), enquanto os países mais distantes referem-se ao Japão (17.653 km), a China (16.914 km) e os Emirados Árabes (11.934km).

Quanto ao poder de compra dos principais parceiros comerciais do Brasil para frutas in natura, cujo PIB constitui-se numa proxy, ressalta-se que, em média, a renda dos países importadores ao longo do período analisado foi de US $\$ 1,524$ 
trilhão. Os Estados Unidos destacam-se com a maior renda entre os países da amostra (aproximadamente US\$ 14 trilhões, em 2007), e o Uruguai, como o país com a menor renda (US $\$ 24,56$ bilhões em 1996). Por sua vez, a renda do Brasil $\left(y_{i t}\right)$, que indica o potencial de oferta de exportação do produto no mercado mundial, apresentou média de 1,36 trilhão de dólares ao longo do período em análise.

\subsection{Desempenho das exportações brasileiras de frutas in natura para os 20 principais importadores}

A Tabela 2 arrola os resultados da taxa exponencial de crescimento das exportações brasileiras de frutas in natura para os 20 países principais importadores e a tendência.

Tabela 2. Evolução das exportações brasileiras de frutas frescas por país importador (1996-2007): análise de tendência e taxa geométrica de crescimento

\begin{tabular}{|c|c|c|}
\hline País importador & Tendência' & Taxa geométrica de crescimento \\
\hline Alemanha & $1.877 .994,0^{* * *}$ & $24,84 \%{ }^{* * *}$ \\
\hline Argentina & $-521.125,7^{\mathrm{NS}}$ & $-4,39 \%$ NS \\
\hline Bélgica & $441.457,3^{* * *}$ & $34,49 \% * * *$ \\
\hline Canadá & $796.919,5^{* * *}$ & $31,11 \%{ }^{* * *}$ \\
\hline China & $9.511,6^{*}$ & $15,95 \%$ NS \\
\hline Emirados Árabes Unidos & $-118.326,6^{* *}$ & $13,24 \%{ }^{* *}$ \\
\hline Espanha & $3.859 .510,0^{* * *}$ & $49,02 \%{ }^{* * *}$ \\
\hline Estados Unidos & $3.794 .144,0^{* * *}$ & $20,71 \%{ }^{* * *}$ \\
\hline França & $617.339,0^{* * *}$ & $15,32 \%{ }^{* * *}$ \\
\hline Irlanda & $351.131,7^{* * *}$ & $28,70 \%{ }^{* * *}$ \\
\hline Itália & $2.031 .558,0^{* * *}$ & $57,15 \%{ }^{* * *}$ \\
\hline Japão & $64.619,93^{* *}$ & $90,72 \%{ }^{*}$ \\
\hline Noruega & $399.298,2^{* * *}$ & $71,54 \%{ }^{* * *}$ \\
\hline Países Baixos & $17.800 .000^{* *}$ & $18,54 \%{ }^{* * *}$ \\
\hline Portugal & $1.883 .229,0^{* * * *}$ & $25,65 \% \%^{* * *}$ \\
\hline Reino Unido & $\begin{array}{r}9.838 .479,0^{* * *} \\
1735083 \mathrm{NS}\end{array}$ & $\begin{array}{l}21,49 \%{ }^{* * *} \\
-3,30 \% N S\end{array}$ \\
\hline $\begin{array}{l}\text { Rússia } \\
\text { Suécia }\end{array}$ & $536.730 .6^{\star \star *}$ & $\begin{array}{l}-3,30 \%^{N S} \\
58,32 \%^{* * * *}\end{array}$ \\
\hline Suíça & $22.723,29^{\mathrm{NS}}$ & $3,28 \%$ NS \\
\hline Uruguai & $162.018,8^{* *}$ & $3,44 \%{ }^{* *}$ \\
\hline
\end{tabular}

Fonte: Resultados da pesquisa.

Notas: ${ }^{* * *},{ }^{* *} e^{* *}$ correspondem, respectivamente, aos níveis de significância de $1 \%, 5 \%$ e $10 \%$ e NS indica coeficiente estatisticamente não significativo.

'Encontra-se a tendência a partir da equação: $Y_{t}=\beta_{0}+\beta_{1} t+\mu_{t}$. A taxa de crescimento exponencial ou geométrica é obtida a partir da equação: $\ln Y_{t}=\beta_{0}+\beta_{1} t+\mu_{t}$. Uma vez estimado o $\beta_{1}$, a taxa de crescimento exponencial, propriamente dita, é calculada utilizando-se $\left[\operatorname{antilog}\left(\beta_{1}\right)-1\right]$. 
Evidencia-se que os principais destinos das exportações brasileiras de frutas são os países desenvolvidos, os quais respondem por $80 \%$ das importações mundiais desses produtos. Oliveira Filho, Costa e Xavier (2008) demonstram, com base em dados da FAO (2005), que países desenvolvidos possuem elevado consumo per capita de frutas. Países como a Espanha, Itália, Alemanha e França, consomem, em média, 120, 115, 112 e 91 quilos anuais per capita, respectivamente. No Brasil, por outro lado, o consumo médio foi, em 2005 , de apenas $57,4 \mathrm{~kg}$, o que representa $47,8 \%$ do consumo espanhol.

Por meio da Tabela 2, observa-se que os países cujo consumo per capita anual é elevado, citados anteriormente, figuram entre os países cujas importações de frutas in natura oriundas do Brasil cresceram a taxas significativamente elevadas no período em análise. Para a Espanha, o crescimento médio das exportações de frutas in natura no período de 1996 a 2007 corresponde a $49 \%$ ao ano (incremento de 3,85 milhões de dólares a. a.), enquanto, para a Itália, alcança 57\% ao ano (aumento de 2,031 milhões de dólares a. a.).

Acerca dos principais importadores, destacados na seção 5.1, cabe ressaltar que a tendência das exportações brasileiras de frutas in natura no período em análise para os Países Baixos foi de incremento de aproximadamente 17,8 milhões de dólares ao ano, o que corresponde à taxa geométrica de crescimento de 18,54\%, enquanto, para o Reino Unido observou-se tendência de aumento das exportações de aproximadamente 9,84 milhões de dólares ao ano (incremento de 21,49\% ao ano).

Por outro lado, países como Noruega, Suécia e Bélgica apresentam as mais elevadas taxas de crescimento das importações de frutas brasileiras. Para a Noruega, ocorreu aumento das exportações brasileiras de frutas de 71,5\% ao ano; para a Suécia, de 58,32\% a. a., e, para a Bélgica, de $34,49 \%$ a. a.

Destaca-se, ainda, que os países em desenvolvimento apresentam as mais modestas taxas de crescimento das importações brasileiras de frutas frescas: Uruguai (3,44\% a. a.), Emirados Árabes (13,24\% a. a.) e China (15,95\% a. a.). Além disso, países como Argentina e Rússia apresentaram, no período estudado, decréscimo das importações de frutas oriundas do Brasil: Argentina (-4,39\% a. a.) e Rússia $(-3,3 \%$ a. a.). 


\subsection{Estimativas dos efeitos das variáveis gravitacionais sobre as exportações brasileiras de frutas frescas}

O modelo de gravidade pressupõe, conforme mencionado na seção 3, que o fluxo de comércio entre dois países é função direta das suas rendas e função inversa da distância entre esses países ${ }^{3}$. Neste estudo, a estimação dos efeitos das variáveis gravitacionais sobre as exportações brasileiras de frutas frescas foi feita pelo método tobit, com efeitos aleatórios e amostras censuradas à esquerda para exportações brasileiras de frutas frescas iguais a zero. Esse método permite, simultaneamente, captar os efeitos de fatores gravitacionais, que não variam ao longo do tempo por unidade cross-section, corroborando a teoria (MADDALA, 2001), e censurar as observações iguais a zero, as quais seriam excluídas da amostra pela impossibilidade de logaritmizar.

Ainda, a exemplo do trabalho de Almeida (2009), utilizou-se, em todas as estimativas, o procedimento de bootstrap como forma de se obterem erros padrão consistentes, uma vez que correções para heterocedasticidade e autocorrelação para modelos de dados em painel utilizando a abordagem tobit não foram encontradas ${ }^{4}$.

A Tabela 3 mostra os resultados da estimação da equação de gravidade para as exportações brasileiras de frutas frescas ao longo do período compreendido entre 1996 e 2007.

Tabela 3. Determinantes das exportações brasileiras de frutas frescas de 1996 a 2007

\begin{tabular}{|c|c|c|}
\hline Variável & Coeficiente & Efeito Marginal \\
\hline Constante & $\begin{array}{l}1,948306^{\mathrm{NS}} \\
(6,733996)\end{array}$ & - \\
\hline Indist $_{i j}$ & $\begin{array}{r}-4,532499^{* * *} \\
(0,46318)\end{array}$ & $\begin{array}{r}-4,532499^{* *} \\
(0,46318)\end{array}$ \\
\hline $\operatorname{lnybr} r_{i t}$ & $\begin{array}{c}6,703714^{* * *} \\
(0,94707)\end{array}$ & $\begin{array}{c}6,703714 \\
(0,94707)\end{array}$ \\
\hline Inyext $_{j t}$ & $\begin{array}{r}0,7113505^{* * *} \\
(0,26352)\end{array}$ & $\begin{array}{c}0,7113505^{*} \\
(0,26352)\end{array}$ \\
\hline Wald Chi2 & 161,61 & \\
\hline Prob. Wald Chi2 & 0,0000 & \\
\hline Número de observações & 240 & \\
\hline \% observações censuradas & $5,83 \%$ & \\
\hline
\end{tabular}

Fonte: Resultados da pesquisa.

Nota: Os valores entre parênteses correspondem aos erros padrão corrigidos por bootstrap. ***, ${ }^{* *},{ }^{*}$ correspondem, respectivamente, aos níveis de significância de $1 \%, 5 \%$ e $10 \%$ e Ns indica coeficiente estatisticamente não significativo. 
Os resultados apontam para o fato de que o aumento em 1\% na distância entre o Brasil e cada país importador reduz, em média, 4,5\% do comércio de frutas frescas brasileiras. Esse resultado é condizente com a teoria econômica, uma vez que a variável geográfica distância está presente no modelo de gravidade como proxy dos custos de comércio: custos e tempo de transporte e custos de informação. Especialmente para o caso em análise, cuja variável dependente consiste nas exportações de frutas frescas, esse coeficiente elevado de sensibilidade das exportações à distância entre os centros produtor e consumidor justifica-se pelo alto grau de perecibilidade dos produtos.

Por outro lado, verifica-se que as variáveis consideradas de atração ao comércio internacional têm afetado positivamente as exportações brasileiras de frutas frescas. No caso da renda nacional, a elevação em $1 \%$ nessa variável acarreta na elevação das exportações de frutas frescas brasileiras em 6,7\%, em média. Esse resultado aponta para a sensibilidade da produção e comércio de produtos diferenciados às variações na renda. Entretanto, como outras variáveis macroeconômicas não foram incluídas no modelo, esse coeficiente elevado da renda deve estar concentrando o efeito de outras variáveis importantes no comércio internacional. A elasticidade das exportações brasileiras de frutas frescas à renda externa apresentou-se menos sensível, indicando que o aumento em $1 \%$ eleva consequentemente as exportações de frutas frescas brasileiras em $0,71 \%$.

Os coeficientes positivos encontrados para as variáveis PIB do país de origem e dos países consumidores de frutas frescas é condizente com os resultados encontrados para outros produtos agropecuários no estudo de Almeida (2012). Segundo a autora, produtos como açúcar, café, soja em grãos, fumo e cortes congelados de carnes suína, bovina e de frango também mostraram-se sensíveis aos aumentos da renda externa. Para todos esses produtos, o coeficiente de elasticidade estimado relacionado à renda externa foi inferior à unidade, como no caso das frutas frescas.

\section{Considerações finais}

Embora o Brasil seja grande produtor de frutas, em termos de mercado mundial, o país não tem encontrado espaço no que se refere ao comércio internacional. $\mathrm{O}$ principal fator motivador refere-se à logística de escoamento da produção, que ainda se apresenta muito precária no país e principalmente, nas regiões fruticultoras. Em um setor onde o bem comercializado apresenta alto grau de perecibilidade, distância e tempo de transporte, tal como condições de armazenagem, tornam-se elementos fundamentais para a competitividade e êxito nas trocas comerciais. 
Existe ainda a questão da qualidade e controle técnico dos produtos exportados. O Brasil ainda é considerado relapso quanto à fiscalização e suporte ao produtor nacional. A falta de padronização de produtos e embalagens e o controle de pragas, eliminam, muitas vezes, portas que demoraram anos para se abrir. A falta de qualidade e controle, somados à logística, são apontados como os maiores entraves das exportações brasileiras de frutas.

Dentre as principais frutas exportadas pelo Brasil, o país é líder mundial na produção de algumas delas, como: abacaxi, laranja e mamão. Contudo, no que diz respeito às exportações, o Brasil não possui liderança em nenhum mercado, apesar de sempre aparecer em posições significativas. Normatizar e investir no setor são pontos fundamentais para o Brasil ganhar posição de destaque nesse espaço altamente competitivo e que abre, somente em determinados períodos do ano, valiosas janelas de mercado.

De acordo com alguns autores, a divulgação das frutas brasileiras e a realização de acordos bilaterais são essenciais para impulsionar o setor fruticultor e acessar mercados emergentes não tradicionais nas relações com o Brasil. Os parâmetros relacionados à quebra de barreiras e à possibilidade de acesso a importantes mercados, como o caso da uva para a Itália e da manga para o Japão, não apresentaram significância estatística. Possivelmente, por não ser um período muito extenso de análise, os resultados advindos desses acordos ainda não foram solidificados e, portanto, não se mostraram impactantes. Os resultados demonstraram que a variável mais elástica do modelo foi a renda interna. Entretanto, essa variável pode estar agrupando a influência de outras variáveis macroeconômicas, suprimidas aqui para não descaracterizar o modelo gravitacional.

No que tange à renda externa, a elasticidade calculada foi menor que 1, mas com valor consideravelmente elevado se comparado a outros trabalhos sobre diversos setores. Isso demonstra a importância da variável no âmbito do comércio internacional de frutas, caracterizando um mercado onde $80 \%$ do total importado são destinados a países desenvolvidos. O coeficiente da variável distância apresentou sinal esperado, ou seja, negativo. Ademais, as exportações do setor caracterizaram-se pela alta sensibilidade em relação a essa variável, corroborando os argumentos de diversos autores que veem na logística, um fator determinante na competitividade do setor frutícola nacional.

Para futuros trabalhos, sugere-se a análise individual de cada fruta e o seu mercado característico. A inclusão de outras variáveis adaptáveis ao modelo gravitacional, como adjacência, língua comum e acordos comerciais, é enriquecedora e torna o trabalho mais elucidativo. Adicionalmente, existe a possibilidade da inclusão dos valores das tarifas cobradas pelos países importadores (barreiras tarifárias) e as notificações de normas requeridas por esses (barreiras não tarifárias). 


\title{
Performance of Brazilian exports of fresh fruit (1996-2007): a gravity model approach
}

\begin{abstract}
This paper evaluates the effects of the distance between Brazil and the importing countries of fresh fruits and of the income of the countries involved in this trade on Brazilian exports of fresh fruits. The analysis is conducted from the perspective of the gravity model, which is the analytical and theoretical tool in this study. The gravity model considers that bilateral trade between countries depends on the gross domestic product, inclunding indicative factors of potential supply and demand of countries, and that the distance between them, a factor of resistance to trade. The results are consistent with the economic theory, ratifying the negative effect of the distance between countries on the trade of fresh fruit, and the positive effect of the gross domestic product of the countries involved in the trade.
\end{abstract}

Keywords: Fresh fruits. Brazilian exports. Gravity model.

\section{Desempeño de las exportaciones brasileñas de frutas en natura (1996-2007): un análisis desde la perspectiva del modelo gravitacional}

\section{Resumen}

En este trabajo se evalúa el efecto de la distancia entre Brasil y los países importadores de frutas en natura y de los ingresos de los países que participan en este comercio de las exportaciones brasileñas de frutas en natura. El análisis se lleva a cabo desde la perspectiva del modelo de gravedad, que es la herramienta analítica y teórica en este estudio. El modelo de gravedad considera que el comercio bilateral entre los países depende del producto interno bruto de los países, que incluye factores indicativos de la oferta y la demanda potencial de los países y de la distancia entre ellos, que es un factor de resistencia para al comercio. Los resultados son consistentes con la teoría económica, lo que confirma el efecto negativo de la distancia entre los países sobre el comercio de fruta fresca y el efecto positivo del producto interno bruto de los países que participan en el comercio.

Palabras clave: Frutas en natura. Comercio internacional. Modelo de gravedad. 


\section{Notas}

1 Banco do Nordeste do Brasil (BNB, 2007 apud OLIVEIRA FILHO; COSTA; XAVIER, 2008).

2 O comércio intraindústria tem como característica a utilização dos mesmos fatores de produção em ambos os países, não sendo explicado pela teoria das vantagens comparativas. O comércio desse tipo depende da capacidade dos países de produzirem bens diferenciados, permitindo ao consumidor escolher o produto com base não só em preço, mas também nas características que mais lhe convêm. Dessa forma, tal modalidade de comércio é explicada pela comercialização de produtos substitutos próximos, porém não idênticos, elaborados por empresas do mesmo ramo industrial (KRUGMAN; OBSTFELD, 2005).

3 Além das variáveis tradicionais consideradas no modelo gravitacional (distância entre os países que comercializam entre si e renda dos mesmos), incluíram-se, na equação (2), variáveis dummy a fim de mensurar os efeitos da liberalização italiana sobre as exportações brasileiras de uva, em 2002, e da liberalização do Japão sobre as exportações brasileiras de manga, em 2005. Estas variáveis não foram estatisticamente significativas nas diversas abordagens da técnica de painel para o modelo de gravidade e, portanto, não foram consideradas nesta análise.

4 Almeida (2009) aponta para a dificuldade de se obterem rotinas de testes de heterocedasticidade e autocorrelação para modelo de dados em painel, com estimação por tobit. Segundo Fred (s.d.), a técnica de bootstrap é utilizada como alternativa na construção de intervalos de confiança de parâmetros em circunstâncias nas quais outras técnicas não são aplicáveis. Assim, a técnica de bootstrap trata a amostra observada como se esta representasse exatamente toda a população e, por meio do processo de reamostragem aleatória, constrói intervalos de confiança.

\section{Referências}

ALMEIDA, F. M. Efeitos dos custos de transporte e das barreiras comerciais no comércio internacional de café verde. $85 \mathrm{f}$. Dissertação (Mestrado em Economia Aplicada) - Universidade Federal de Viçosa, Viçosa, MG, 2009.

ALMEIDA, F. M. Medidas não tarifárias e comércio internacional agrícola: os efeitos dos objetivos das notificações aplicadas aos acordos TBT e SPS. 129 f. Tese (Doutorado em Economia Aplicada) - Universidade Federal de Viçosa, Viçosa, MG, 2012.

AZEVEDO, André Filipe Zago de. O Efeito do Mercosul sobre o Comércio: Uma Análise com o Modelo Gravitacional. Pesquisa e Planejamento Econômico, v. 34, n. 2, p. 307-339, 2004.

BERGSTRAND, J. H.. The generalized gravity equation monopolistic competition, and the factor proportions theory in international trade. Review of Economics and Statistics, n.71, p. 143153, 1989.

CASTILHO, M. R. O acesso das exportações do Mercosul ao mercado europeu. Pesquisa e Planejamento Econômico, Rio de Janeiro, RJ, v. 32, n. 1, 149-198, 2002.

DEARDOFF, A. V. Determinants of bilateral trade: does gravity work in a neoclassical world? In: The Regionalization of the World Economy, Ed. Jeffrey A. Frankel. Chicago: Chicago University Press, 1998.

FAVERET FILHO, P.; ORMOND, J. G. P.; de PAULA, S. R. L. Fruticultura brasileira: a busca de um modelo exportador. BNDES, Rio de Janeiro, 1999.

FLACH, L. Uma análise em modelo gravitacional para os determinantes do investimento direto externo no Brasil. 96 f. Monografia (Graduação em Ciências Econômicas) - Universidade Federal de Santa Catarina. 2008. Disponível em: <http://www.cofecon.org.br/dmdocuments/SPASS.pdf > . Acesso em: 08 abr. 2009. 
FOOD AND AGRICULTURE ORGANIZATION OF THE UNITED NATIONS. Disponível em < http://www.fao.org/corp/statistics/en/>. Acesso em: 08 abr. 2009.

FRATIANNI, M. The gravity equation in internacional trade. Handbook of Internacional Bussiness, 2. ed., Oxford University Press, 2007.

GAYET, J. P. Receita para crescer. Agroanalysis. v. 19, n. 1, Rio de Janeiro: janeiro de 1999. p. 39-43.

GOEBEL, D. A competitividade externa e a logística doméstica. In: $O$ desafio das exportações. BNDES. 1. ed. Rio de Janeiro. 2002.

GONÇALVES, J. S.; SOUZA, S. A. M. Por que o Chile exporta mais frutas frescas que o Brasil? SED, 1998.

GOOGLE. Google Earth 5. Disponível em <http://earth.google.com/intl/pt>. Acesso em: 10 mai. 2009.

HIDALGO, Álvaro Barrantes; VERGOLINO, J. O Nordeste e o comércio inter-regional e internacional: um teste dos impactos por meio do modelo gravitacional. Revista de Economia Aplicada, Ribeirão Preto, SP, v. 2, n. 4, p. 707-725, 1998.

INSTITUTO BRASILEIRO DE FRUTAS. Disponível em <www.ibraf.org.br>. Acesso em: 23 fev. 2010.

INTERNATIONAL MONETARY FOUND. World Economic Outlook Databases. Disponível em < http://www.imf.org/external/ns/cs.aspx?id=28>. Acesso: 14 jun. 2009.

JAYME JR, F. G. Comércio Internacional e Crescimento Econômico: o comércio afeta o desenvolvimento? Revista Brasileira de Comércio Exterior, Rio de Janeiro, RJ, v. 15, n. 69, p. 69-73, 2001.

JÓRDAN, J.; PARRÉ, J. L. Dinâmica das exportações da América Latina: economias de escala ou dumping recíproco? Revista de Economia Aplicada, São Paulo, v. 10, n. 4, p. 589-607, 2006.

KRUGMAN, P. Scale economies, product differentiation, and the pattern of trade. American Economic Review, v. 70, 1980.

MADDALA, G. S. Introdution to econometrics. Macmillam Publishing Company: New York, 2. ed. 1992.

MATA, D.; FREITAS, R. E. Produtos Agropecuários: para quem exportar? Revista de Economia e Sociologia Rural, Brasília, DF, v. 46 n. 2, 2008. Disponível em: <C: \Users $\backslash W s \backslash D o c u m e n t s \backslash$ Mestrado Economia Aplicada \Artigo TPE \da mata e freitas.mht>. Acesso em: 27 abr. 2009.

MINISTÉRIO DO DESENVOLVIMENTO, INDÚSTRIA E COMÉRCIO EXTERIOR, Secretaria do Comércio Exterior (Secex). Disponível em: http://www2.desenvolvimento.gov.br/sitio/secex/secex/competencia.php. Acesso em: 23 abr. 2009.

NACHREINER, M. L.; SANTOS, R. R. P.; BOTEON, M. Janelas de mercado: a fruticultura brasileira no mercado internacional. In: Sociedade Brasileira de Economia e Sociologia Rural, 2003, Juiz de Fora. XLI Congresso Brasileiro de Economia e Sociologia Rural, 2003.

NEVES, E.M. et al. Citricultura brasileira: efeitos econômico-financeiros 1996-2000. Revista Brasileira de Fruticultura, v. 23, n. 2, p. 432-436, agosto. 2001.

OLIVEIRA FILHO, S. F. S.; COSTA, E. F.; XAVIER, L. F. Diversificação da produção e acesso a mercados: estudo de caso para a fruticultura irrigada do Pólo Petrolina-Juazeiro. In: XLVI Congresso da Sociedade Brasileira de Economia, Administração e Sociologia Rural, 2008, Rio

Teoria e Evidência Econômica - Ano 19, n. 41, p. 9-34, jul./dez. 2013 
Branco-AC. Anais do XLVI Congresso da Sociedade Brasileira de Economia, Administração e Sociologia Rural, 2008.

PASSONI, A. C. et al. Análise dos principais entraves na exportação de frutas brasileiras. XLIV Congresso da Sober. Fortaleza: 23 a 27 de julho de 2006. 11p.

PIANI, G.; KUME, H. Fluxos Bilaterais de Comércio e Blocos Regionais: uma aplicação do modelo gravitacional. Texto para discussão n. 749, Instituto de Pesquisa Econômica Aplicada (IPEA), Rio de Janeiro, RJ, 2000.

PORTER, M. Estratégica competitiva: técnicas para análise de indústria e da concorrência. 7. ed. Rio de Janeiro: Campus, 1993.

SANTOS, F. L. Desempenho recente da fruticultura brasileira no cenário internacional: a participação da política comercial e dos programas de apoio na retomada do market share. Informações Econômicas, SP, v. 35, n. 5, maio 2006.

WOOLDRIDGE, J. M. Introdução à econometria: uma abordagem moderna. 2. ed. São Paulo: Cengage Learning, 2008. 684 p.

ZERBIELLI, J. ; WAQUIL, P. D. O papel das instituições e do ambiente institucional na inserção da fruticultura brasileira no Mercosul. In: XLIII Congresso Brasileiro de Economia e Sociologia Rural, 2005, Ribeirão Preto, SP. Instituições, Eficiência, Gestão e Contratos no Sistema Agroindustrial. Brasília, DF: SOBER, 2005. p. 1-19.

APÊNDICE 1 - Países importadores de frutas frescas brasileiras considerados na amostra

1-Alemanha
2-Argentina
3 - Bélgica
4- Canadá
5 - China
6 - Emirados Árabes Unidos
7 - Espanha
8- Estados Unidos
9 - França
10 - Irlanda
11 - Itália
12 - Japão
13 - Noruega
14 - Países Baixos
15 - Portugal
16 - Reino Unido
17 - Rússia
18 - Suécia
19 - Suíça
20 - Uruguai 